\title{
Effects of Lead on Delta-aminolevulinic Acid Dehydratase Activity of Erythrocyte and Tissues in Pregnant and Nonpregnant Rats. I. Administration of Lead in High Concentration
}

\author{
Masatoshi HAYASHI \\ Department of Hygiene, Dokkyo University School of Medicine, \\ 880 Kitakobayashi, Mibu-machi, Shimotsuga-gun, \\ Tochigi, 321-02 Japan
}

(Received October 15, 1981)

\begin{abstract}
Pregnant and nonpregnant rats were administered $500 \mathrm{ppm}$ of lead in drinking water for 23 days. Pregnant and nonpregnant rats administered distilled water served as controls. Red blood cell counts, hematocrit and hemoglobin were significantly decreased in the pregnant rats, but there were no significant differences between the control and the lead-treated group. Erythrocyte delta aminolevulinic acid (ALAD) activity was significantly reduced in the lead-treated group. In the lead-treated group, there was tendency for stronger depression of erythrocyte ALAD activity in pregnant rats. Furthermore, ALAD activity of the liver and spleen were significantly decreased in the lead-treated pregnant rats. In the lead-treated group, the lead $(\mathrm{Pb})$ concentrations of blood, liver and spleen were higher in pregnant than in nonpregnant rats. The erythrocyte ALAD activity is negatively correlated with the blood $P b$ concentration in pregnant and nonpregnant rats. $A$ statistically significant correlation between the ALAD activity and the Pb concentration of the tissues were observed only in pregnant rats. These results indicate that special avoidance of lead exposure should be required for mothers during pregnancy.
\end{abstract}

Keywords : ALAD activity-Lead poisoning-Pregnant and nonpregnant ratsErythrocyte-Blood-Tissues

\section{INTRODUCTION}

Although lead poisoning has long been regarded as an occupational disease frequently encountered in workers making electric battery and compositors, it now becomes a social issue because the risk of being exposed to lead for the public health becomes serious due to lead derived from exhaust gas in environmental pollution since lead was added to gasoline as an anti-knock preparation ${ }^{1-3)}$. On the other hand, the sensitivity against lead in vivo is higher with lower ages ${ }^{4,5)}$, especially adverse reactions including deformation or cerebral disturbance may 
appear in fetus and/or new born babies when the pregnant mother was exposed to lead $^{6,7)}$. From these facts, a lot of interest has been paid to lead exposure in pregnancy. However, either of these concerns were mainly on the influence of lead on fetus and almost no study is available for the sensitivity to lead of mother's own changes during pregnancy. In the present study, therefore, the influence of lead-containing water at relatively high concentrations administered to pregnant and nonpregnant rats was determined by examining various biochemical index.

\section{Materials AND Methods}

Adult female Wistar rats were divided into pregnant and nonpregnant. Pregnant and nonpregnant rats were further subdivided into control and lead-treated groups, and given distilled water and distilled water containing $500 \mathrm{ppm}$ of lead as lead acetate, respectively. In pregnant rats each group was administered from 1st (day when the sperm was found in the vaginal smear) to 23 days of gestation and were sacrificed on 15,18, 21 and 2.3 days of gestation. Nonpregnant rats were administered for the same periods and sacrificed on the same day as pregnant rats.

Blood samples were collected form abdominal cava. Liver and sp'een were removed by dissection. Red blood cell (RBC) counts was estimated by a micro cell counter. Hemoglobin $(\mathrm{Hb})$ concentration was determined with the cyanmethemoglobin method and hematocrit $(\mathrm{Ht})$ value by means of heparinized microcapillary tubes, which were centrifuged at $12,000 \mathrm{rpm}$ for 5 minutes. The whole blood and homogenized tissues were ashed and digested in an acid solution ${ }^{8}$. All samples were assayed by a flameless atomic absorption spectrophotometer. The activity of delta-aminolevulinic acid dehydratase (ALAD) of the erythrocyte and tissues were measured according to Itaya et al. ${ }^{9}$

\section{RESULTS}

\section{Hematological data.}

The $\mathrm{RBC}$ counts, $\mathrm{Ht}$ value and $\mathrm{Hb}$ concentration in each group of pregnant and nonpregnant rats were given in Table 1 . The hematological data in nonpregnant rats as control group showed the total values from 15 to 23 days. The $\mathrm{RBC}$ counts, $\mathrm{Ht}$ value and $\mathrm{Hb}$ concentration were significantly lower in pregnant rats than in nonpregnant rats, but was not significant difference between the control and the lead-treated groups, regardless of pregnancy.

\section{ALAD activity of erythrocyte and tissues.}

The ALAD activity erythrocyte, liver and spleen are presented in Table 2. The erythrocyte ALAD activity in nonpregnant rats significantly decreased in the lead-treated group compared to the control group on the each day of autopsy 
Table 1. Hematological values of nonpregnant and pregnant rats (mean \pm S.D.)

\begin{tabular}{|c|c|c|c|c|c|c|c|c|}
\hline \multirow[b]{2}{*}{ Group } & \multirow[b]{2}{*}{ Day } & \multirow[b]{2}{*}{$\mathbf{N}$} & \multicolumn{3}{|c|}{ Nonpregnant rat } & \multicolumn{3}{|c|}{ Pregnant rat } \\
\hline & & & $\begin{array}{c}\mathrm{RBC} \\
\left(10^{6} / \mathrm{mm}^{3}\right)\end{array}$ & $\underset{(\%)}{\mathrm{Ht}}$ & $\underset{(\mathrm{g} / \mathrm{d} l)}{\mathrm{Hb}}$ & $\begin{array}{c}\text { RBC } \\
\left(10^{6} / \mathrm{mm}^{3}\right)\end{array}$ & $\underset{(\%)}{\mathrm{Ht}}$ & $\begin{array}{l}\mathrm{Hb} \\
(\mathrm{g} / \mathrm{d} l)\end{array}$ \\
\hline \multirow[t]{4}{*}{ Control } & 15 & 5 & \multirow{4}{*}{$654 \pm 61$} & \multirow{4}{*}{$40.9 \pm 1.5$} & \multirow{4}{*}{$13.2 \pm 0.8$} & $544 \pm 19^{a} * * *$ & $39.2 \pm 3.6$ & $11.0 \pm 1.3^{\mathrm{a} * * *}$ \\
\hline & 18 & 5 & & & & $558 \pm 16^{a * *}$ & $37.2 \pm 1.4^{\mathrm{a} * * *}$ & $11.6 \pm 1.0^{\mathrm{a} * * *}$ \\
\hline & 21 & 5 & & & & $512 \pm 42^{\mathrm{a} * * *}$ & $33.4 \pm 2.3^{a * * *}$ & $10.5 \pm 0.8^{\mathrm{a} * * *}$ \\
\hline & 23 & 5 & & & & $513 \pm 43^{a * * *}$ & $34.4 \pm 3.1^{\mathrm{a} * * *}$ & $10.5 \pm 0.7 \mathrm{a} * * *$ \\
\hline \multirow[t]{4}{*}{ Experiment } & 15 & 5 & $646 \pm 20$ & $43.1 \pm 2.4$ & $13.3 \pm 0.8$ & $559 \pm 59$ & $36.5 \pm 5.1^{\mathrm{a} *}$ & $11.2 \pm 2.1$ \\
\hline & 18 & 5 & $629 \pm 243$ & $39.3 \pm 0.6$ & $12.5 \pm 0.5$ & $558 \pm 32^{a * *}$ & $36.6 \pm 1.8^{\mathrm{a} * *}$ & $11.4 \pm 0.7^{a *}$ \\
\hline & 21 & 5 & $652 \pm 19$ & $39.8 \pm 2.4$ & $13.0 \pm 9.8$ & $447 \pm 61^{\mathrm{a} * * *}$ & $30.0 \pm 2.5^{a * * *}$ & $9.2 \pm 0.9^{a * * *}$ \\
\hline & 23 & 5 & $655 \pm 17$ & $40.7 \pm 2.0$ & $13.1 \pm 0.7$ & $529 \pm 66^{a * *}$ & $34.4 \pm 2.7^{\mathrm{a} * *}$ & $11.1 \pm 0.8^{\mathrm{a} * *}$ \\
\hline
\end{tabular}

a Significant difference from nonpregnant rat $\left({ }^{*} \mathrm{p}<0.05, * * \mathrm{p}<0.01, * * *<0.001\right)$.

and showed $84.1 \%$ inhibition on day 23. The ALAD activity of the liver and spleen were, however, not significantly different between the control and the lead-treated groups. In pregenant rats, the erythrocyte ALAD activity significantly decreased in the lead-treated group on the each day of pregnancy and the inhibition degree reached to $92.6 \%$ as compared with the control value on 23 rd day of pregnancy.

The liver ALAD activity in pregnant rats was not statisticaily significantiy different between the control and the lead-treated groups up to the 21 st day of pregnancy but in the lead-treated group the $43.4 \%$ inhibition on the 23 rd day of pregnancy was significant $(\mathrm{p}<0.01)$. The ALAD activity of spleen in the leadtreated group showed 24.0\% (not significant) and $78.6 \% \quad(\mathrm{p}<0.001)$ inhibition on day 15 and 23 of pregnancy, respectively.

In the control group the ALAD activity of erythrocyte and tissues were significantly higher in pregnant rats than in nonpregnant rats except for the erythrocyte ALAD activity on day 21 and 23 of pregnancy. On the other hand, in the leadtreated group the ALAD activity of erythrocyte and tissues were significantly higher in pregnant rats than in nonpregnant rats up to the 21 st day of pregnancy, bu a significant reduction of the ALAD activity of erythrocyte, liver and spleen was found in pregnant rats on the 23rd day of pregnancy.

\section{Lead concentrations of blood and tissues.}

Lead concentrations of blood, liver and spleen in pregnant and nonpregnant rats are shown in Table 3. In the control group, the $\mathrm{Pb}$ concentration of each sample had no significant differences between pregnant and nonpregnant rats. In the lead-treated group, the $\mathrm{Pb}$ concentration of each sample was significantly higher in pregnant rats than in nonpregnant rats except for the spleen $\mathrm{Pb}$ concentration on day 15 of pregnancy. Regardless of pregnancy, the $\mathrm{Pb}$ concentration showed higher in the lead-treated than in the control groups. 


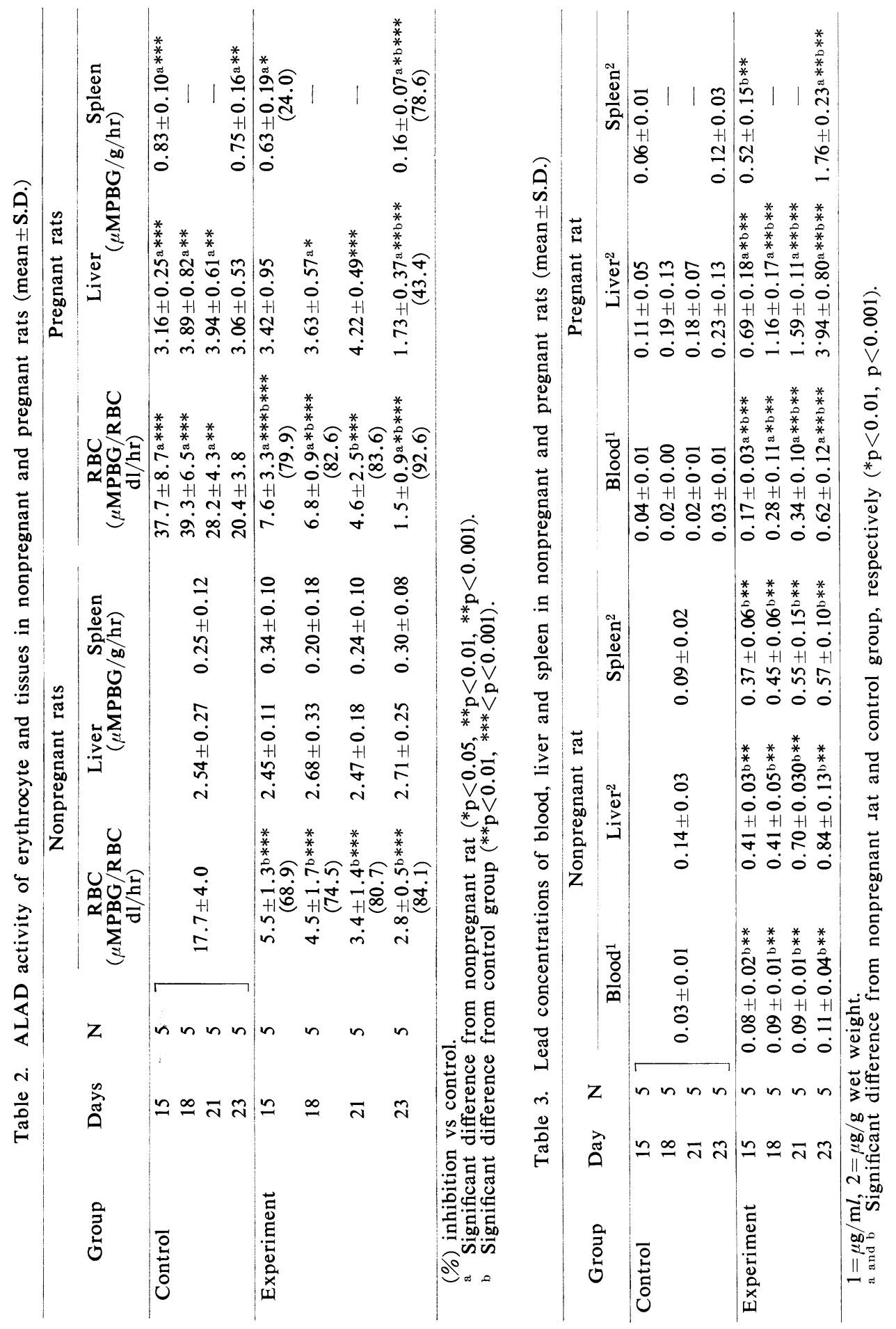




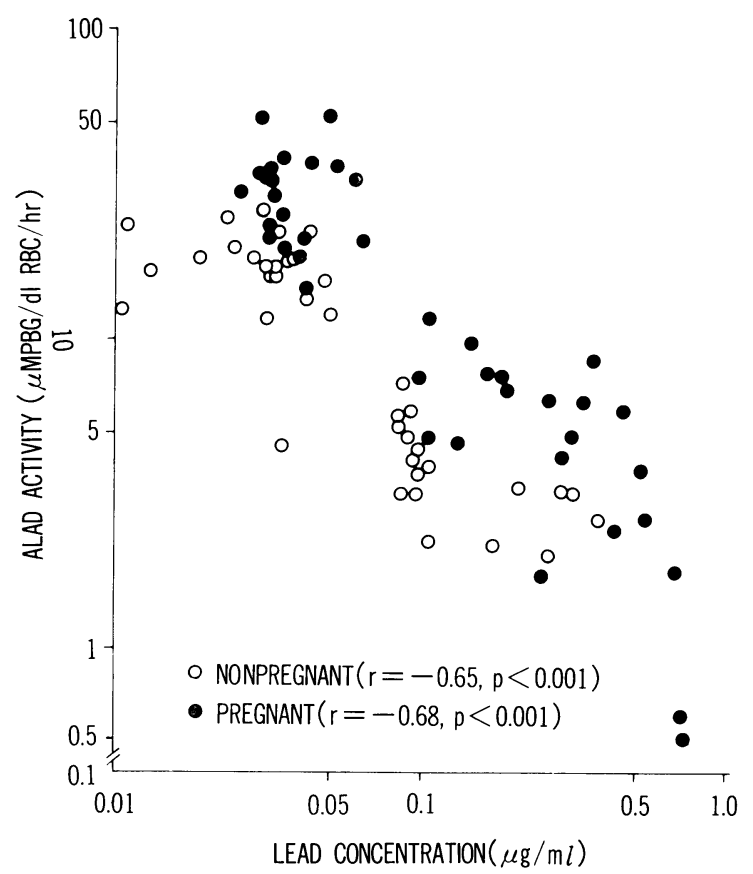

Fig. 1. Correlation between erythrocyte ALAD activity and blood lead concentration in pregnant and nonpregnant rats.

Statistical correlation.

A statistically significant negative correlation was found between the erythrocyte ALAD activity and the blood $\mathrm{Pb}$ concentration in pregnant and nonpregnant rats (Fig. 1). There was no statistically significant correlation between the ALAD activity and the $\mathrm{Pb}$ concentration of liver or spleen in nonpregnant rats (Figs. 2 and 3). The correlation coefficients of ALAD activity with $\mathrm{Pb}$ concentration of liver and spleen in pregnant rats were -0.53 and -0.69 respectively (Figs. 2 and 3). No correlation between the erythrocyte and the liver ALAD activity was observed, in both pregnant and nonpregnant rats. Furthermore, significant correlations between erythrocyte and spleen ALAD activity or liver and spleen ALAD activity in the nonpregnant rats was not found. There, however, were high correlations between the ALAD activities of erythrocyte and spleen or of liver and spleen in pregnant rats. These correlation coefficients were $-1-0.62$ and +0.47 respectively.

\section{Discussion}

Regardless of lead treatment, $\mathrm{RBC}$ counts, $\mathrm{Ht}$ and $\mathrm{Hb}$ showed a significant decrease in pregnant rats as compared to those in nonpregnant rats. However, no significant difference was noted in either pregnant or nonpregnant rats when 


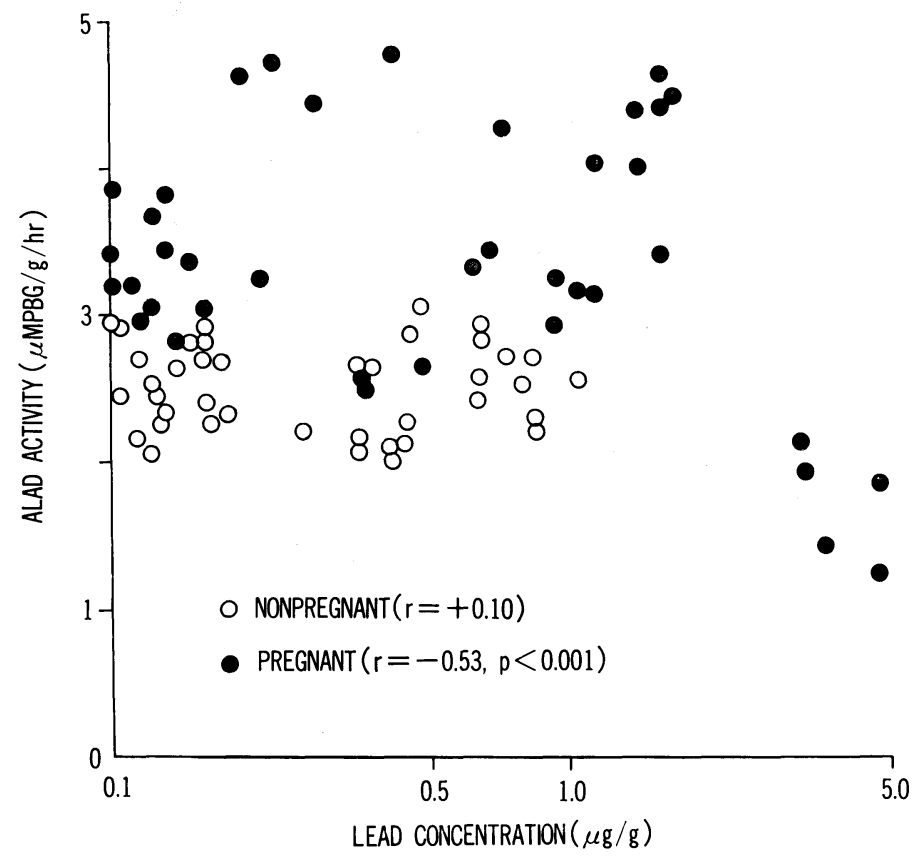

Fig. 2. Correlation between ALAD activity and lead concentration of liver in pregnant and nonpregnant rats.

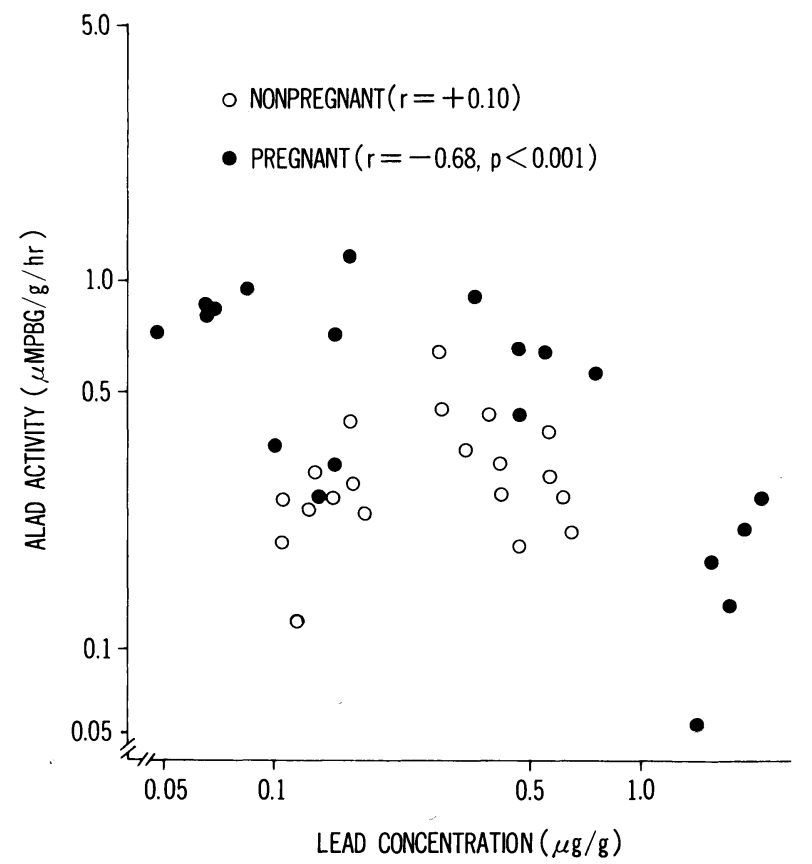

Fig. 3. Correlation between ALAD activity and lead concentration of spleen in pregnant and nonpregnant rats. 
comparison was made between the control and the lead-treated groups. Thus, the decrease of these parameters noted in pregnant rats was considered not to be attributable to lead treatment but to physiological change due to pregnancy. It is, however, said that the hematological changes of mature animals generally appear when the lead exposure in large $\operatorname{doses}^{10)}$ or for long terms ${ }^{11)}$ so that even a small dose as $500 \mathrm{ppm}$ may produce bad influences in species having long gestation periods.

Erythrocyte ALAD activity is one of the most vaiuable indexes as an early diagnosis of lead poisoning because of its higher susceptibility to lead ${ }^{12,13}$. In the present study, erythrocyte ALAD activity was remarkably reduced in the lead-treated group and in particular, pregnant rats showed a significant suppression as compared to nonpregnant rats. In addition, blood $\mathrm{Pb}$ level was also high in the leaed-treated group irrespective of pregnancy and was higher in pregnant rats than in nonpregnant rats. The increased blood $\mathrm{Pb}$ level in pregnant rats considered probably attributable to increased water intake due to pregnancy, which may result in a more potent suppression of erythrocyte ALAD activity.

Since a significant decrease of ALAD activity in the liver and spleen was noted in the lead-treated pregnant rats on the 23rd day of pregnancy, the suppression of this enzymatic activity in these tissues seemed to occur when the tissue $\mathrm{Pb}$ level increased to about 15-17 times that in the control group. The experimental result concerning erythrocyte ALAD activity and blood and tissue $\mathrm{Pb}$ levels obtained from this study corresponded well with the findings described by Prigge et al. ${ }^{14}$ ) and Prigge and Grove ${ }^{15}$, however, they did not report on ALAD activity in tissue.

Because ALAD activity in erythrocytes or tissue generally increase during anemia ${ }^{16,17)}$, the increased ALAD activity detected in pregnant rats may relate to the increased heme-synthesis as a feed-back due to the decreased heme concentration accompanied with the decrease of hematocytes ${ }^{18}$.

With respect to the relation of ALAD activity to $\mathrm{Pb}$ concentration, a significant negative correlation was demonstrated between the erythrocyte ALAD activity and the blood $\mathrm{Pb}$ level in both pregnant and nonpregnant groups. A significant negative correlation also existed between the ALAD activity and the $\mathrm{Pb}$ concentration in the liver and spleen, however, it was noted only in pregnant rats. In addition, although a positive correlation was demonstrated between ALAD activities of the spleen and erythrocytes, no such relation could be noted between ALAD activities of the liver and erythrocytes. This finding indicates that the sensitivity of ALAD against lead is similar $n$ the spleen and erythrocytes but dssimilar to that in the liver.

Erythrocyte ALAD activity in the lead-treated group was strongly suppressed in pregnant rats, however, the suppression of this enzyme activity surely occurred at lower $\mathrm{Pb}$ levels in nonpregnant rats when considered the blood $\mathrm{Pb}$ level. Therefore, the susceptibility of erythrocyte ALAD against lead might be higher in nonpregnant rats as compared to pregnant rats. From the evidence of potent 
suppression of erythrocyte ALAD activity in addition to considerable suppression of ALAD activity in the liver or spleen was observed in pregnant rats in addition to the physiologically decreased $\mathrm{RBC}$ counts, $\mathrm{Ht}$ and $\mathrm{Hb}$, it was considered that special attention should be paid to lead exposure to mothers during pregnancy.

\section{RefERENCES}

1) Kinard, J.T., Tisdale, J. and Alexander, E. (1976). J. Eviron. Health, 2, 153.

2) Piver, W.T. (1977). Environ. Health Perspect., 19, 247.

3) Tuchiya, K., Okubo, T., Nagasaki, M., Nakajima, T., Kamijo, H. and Mizoguchi, I. (1977). Int. Arch. Occup. Environ. Health, 38, 247.

4) Maruta, H. (1977). Jap. J. Ind, Health, 19, 67. (in Japanese).

5) McCabe, E.B. (1979). Environ. Health Perspect., 29, 29.

6) McClain, R.M. and Becker, B.A. (1975). Toxicol. Appl. Pharmacol., 31, 72.

7) Press, M.F. (1977). J. Neuropathol. Exp. Neurol., 36, 169.

8) Coulston, F. and Korte, F. (1975). Environmental Quality and Safety, Lead, Georg. Thieme Pub./Academic Press, New York.

9) Itaya, K., Mitani, K., Hoshino, M. and Kondo, M. (1974). Jap. J. Ind. Health, 16, 276, (in Japanese).

10) Cardona, E. and Lessler, M.A. (1974). Proc. Soc. Exp. Biol. Med., 145, 663.

11) Kennedy, G.L., Arnold, D.W. and Calander, J.C. (1975). Fd. Cosmet. Toxicol., 13, 629.

12) Hirano, H., Hanazawa, K., Ishikawa, K., Hirashima, N., Usui, S. and Yoshino, K. (1979). Jap. J. Ind. Health, 21, 408. (in Japanese).

13) Wada, O., Yano, Y. and Toyokawa, K. (1973). Ind. Health, 11, 55.

14) Prigge, E., Baumert, H.P., Hochrainer, O. and Oberdorter, G. (1977). Zentrabl. Bakteriol. Orig. B, 165, 283.

15) Prigge, E. and Grove, J. (1977). Zenırabl. Bakteriol. Orig. B, 165, 294.

16) Campbell, B.C., Meredith, P.A., Moore, M.R. and Goldberg, A. (1978). Brit. J. Haematol., 40, 397.

17) Battistini, V., Morrow, T.J·, Ginsburg, D., Thompson, G., Moore, M.R. and Goldberg, A. (1971). Brit. J. Haematol., 20, 177.

18) Ibrahim, N.G., Gruenspecht, N.R. and Freedman, M.L. (1978). Biochem. Biophy. Res. Commun., 80, 722. 